\title{
Third Quarter Business Developments
}

E failed to provide conclusive answers to two significant questions about the current direction of economic activity. Is the economy headed toward a full-fledged recession or only a temporary slowing in the rate of growth of real output? When will inflationary pressures recede?

Production growth slowed in the third quarter from the rate observed over the first half of the year, but only to about its trend growth rate. The implicit GNP price deflator rose more slowly in the third quarter of 1973 than in the second, but the rate of increase was greater than for any single quarter in the 1951-1972 period. Business fixed investment rose rapidly in the third quarter, suggesting considerable strength in the economy to some analysts; however, weakness in the housing and consumer durable goods' areas provide conflicting evidence. This article reports on recent rates of growth of GNP and its components, production, employment, and prices.

\section{Total Spending and GN Components}

Total spending increased at a 10.4 percent annual rate from the second to the third quarter of 1973 , compared to a 9.8 percent rate of increase from the first to the second quarter and a 15.2 percent rate in the preceding quarter. To place the third quarter gain in perspective, it is instructive to note that it was about the same as the ten percent rate of increase from the fourth quarter of 1970 -the quarter in

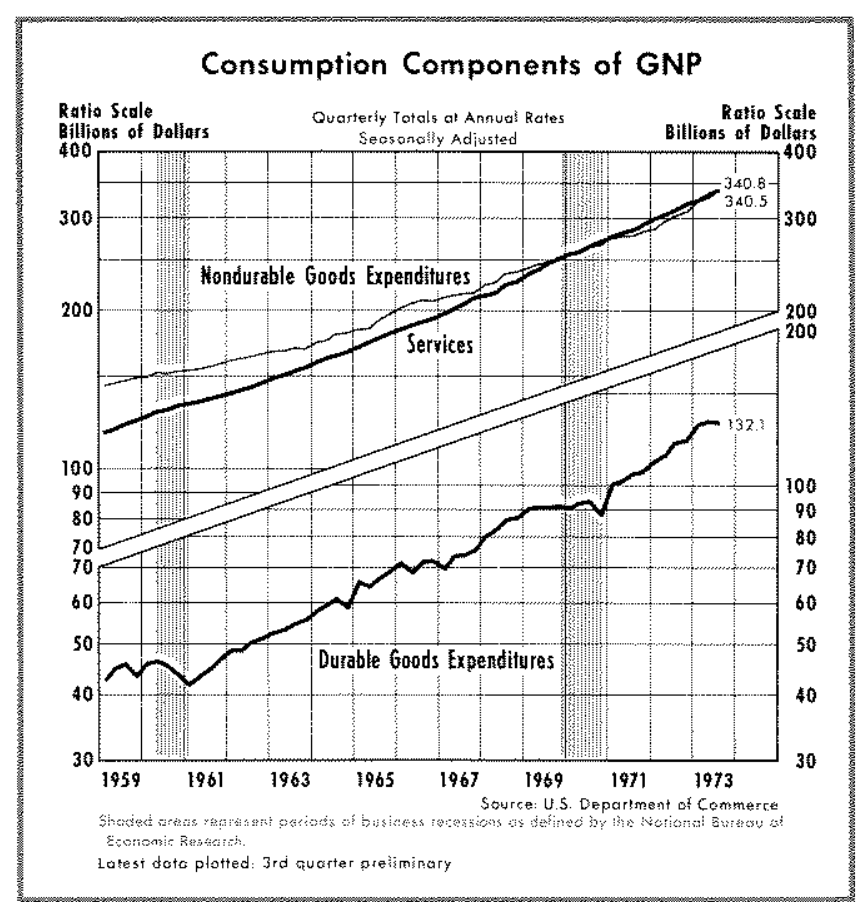

which the latest period of economic expansion began - to the fourth quarter of 1972.

Consumption - Personal consumption expenditures, the largest component of GNP, accounted for 62.6 percent of total spending in 1972. These expenditures rose at a 9.3 percent annual rate from the second to the third quarter of 1973 , little changed from the average rate of growth recorded over the past two and one-half years of economic expansion. Expendi- 
tures for non-durable consumption goods expanded at a rapid 13.3 percent annual rate in the third quarter, after rising 9.7 percent in the previous year. The growth of expenditures on all durable goods has shown little change since the first quarter of this year, reflecting, in part, the decline in expenditures for new automobiles in the second and third quarters. From fourth quarter 1970 to first quarter 1973, expenditures on durable goods increased at nearly a 20 percent average annual rate.

Thestment - Gross private domestic investment, which includes total fixed investment and the change in inventories, expanded at an 18.3 percent rate in the third quarter. Investment in residential structures declined for the first time in thirteen quarters, while investment in nonresidential structures continued to expand at a brisk pace.

Investment in residential structures increased by a rapid 40.7 percent from second quarter 1970 to second quarter 1971, but has since decelerated. The growth in residential investment slowed from a 27.2 percent increase for the year ending second quarter 1972 to a 12.9 percent rise in the following year. Residential investment declined slightly from the second to the third quarter of this year.

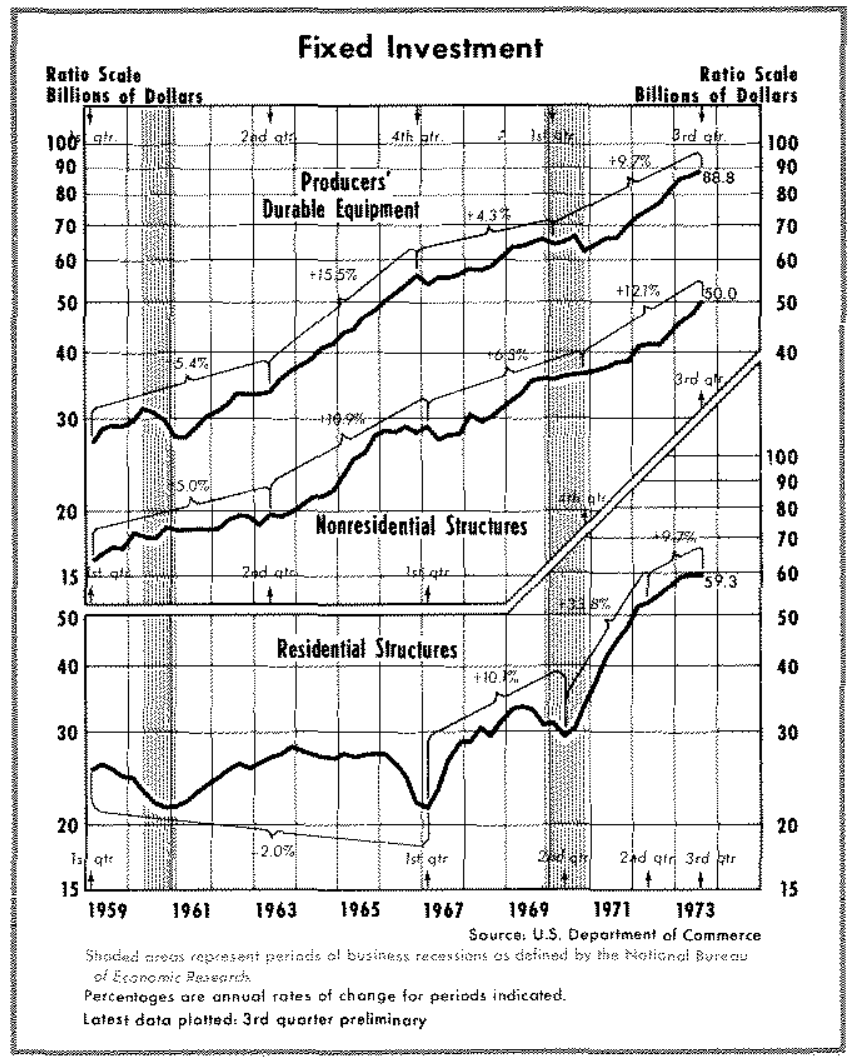

By way of contrast, investment in nonresidential structures and producers' durable equipment has ac- celerated since the $1969-70$ recession. Investment in nonresidential structures rose 9.6 percent in the year ending fourth quarter 1971, advanced 15.1 percent in 1972, and registered a 15.7 percent rate of increase in the first three quarters of 1973 .

Goverment Spending - Total government purchases of goods and services expanded at a 9.9 percent rate in the first three quarters of 1973, compared to a 7.6 percent increase in 1972 and a trend rate of 9.3 percent from 1965 to 1972 . Federal Government purchases declined slightly in the third quarter to a $\$ 107.1$ billion annual rate, little changed from the magnitude of such expenditures in the second quarter of 1972. Since 1968, a relatively slow rate of growth has been recorded for Federal Government purchases of goods and services.

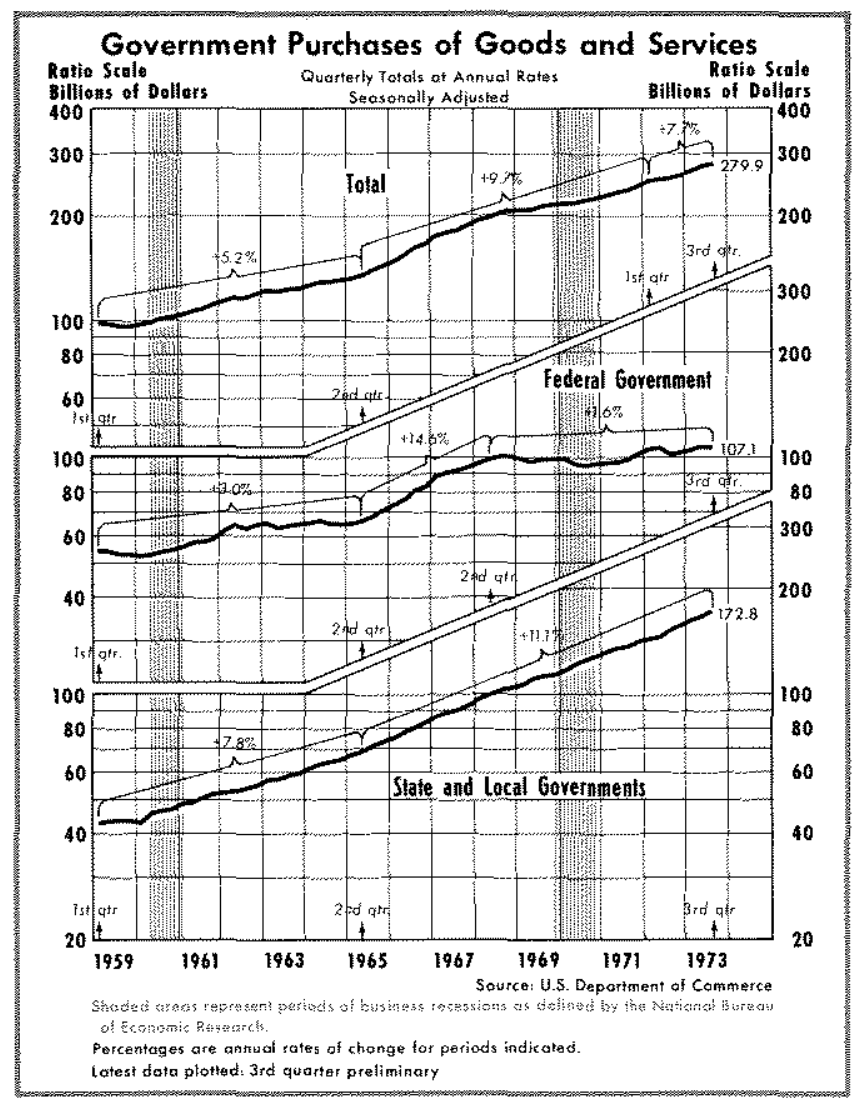

State and local government purchases were at a $\$ 172.8$ billion annual rate in the third quarter, an 11.9 percent annual rate of gain from the second quarter. These purchases expanded 13.9 percent from second quarter 1972 to second quarter 1973, compared to a trend rate of 11.5 percent from 1965 to 1972 .

Net Exports - Net exports of goods and services (exports minus imports) were positive in the first three quarters of 1973 , compared with negative balances for the previous five quarters. On balance, net 
exports declined during 1971 and 1972, but have been increasing since second quarter 1972. Two official devaluations of the dollar occurred in this time period -. one in December 1971 and another in February 1973. From third quarter 1972 to third quarter 1973 , exports rose almost 39 percent while imports rose 27.2 percent.

\section{Produchion and Emplomment}

Real product rose at a 3.5 percent rate in the third quarter of 1973 , compared to a 5.5 percent rate of increase in the first two quarters of the year. The pace of real activity in the most recent quarter is little different from the 3.8 percent average rate recorded over the $1957-72$ period, but is substantially below the 6.3 percent rate of increase in the two-year period of economic recovery through the fourth quarter of 1972 .

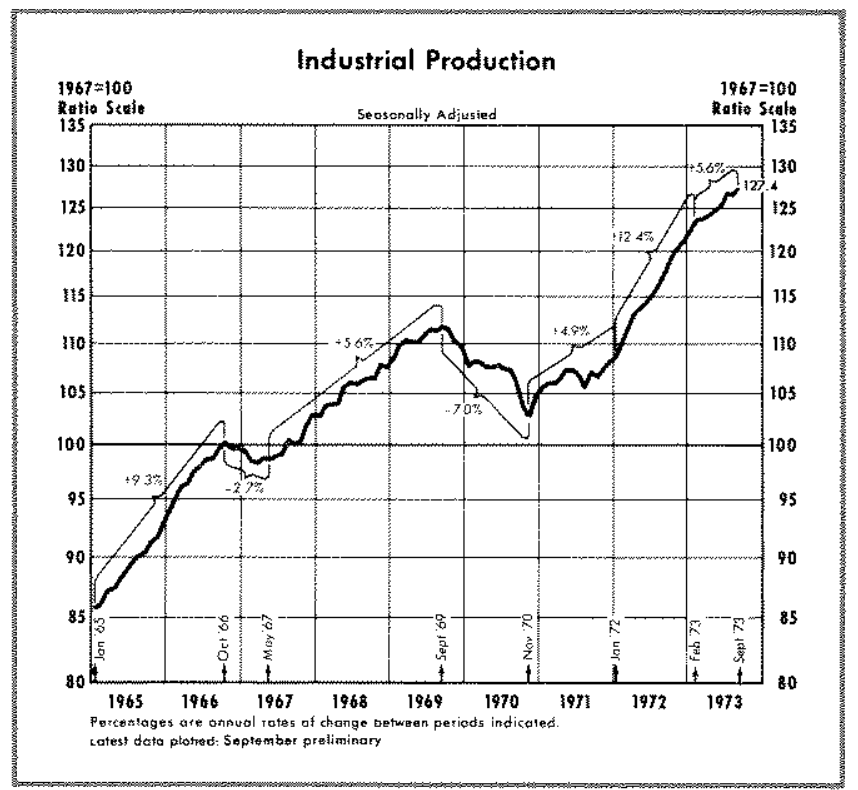

The pattern of industrial production growth in recent months has been similar to that of real product.
Industrial production growth accelerated to a 6.6 percent rate in the third quarter of 1973, after dropping from a 10.1 percent rate of increase in the first quarter to a 5.9 percent rate in the second quarter. Industrial production increased at a 4.2 percent average annual rate from 1957 to 1972 .

Continuing strength in the economy was also indicated by the rise in employment over the past several months. Total civilian employment rose at a 4.8 percent rate from May 1973 to October, compared to a 3.6 percent rate in the first five months of the year and a 1.6 percent trend rate over the previous 15 years.

Relatively high rates of labor and capital utilization continued into the third quarter of 1973 . Unemployment, which averaged 5 percent of the civilian labor force in the first two quarters of the year, stood at 4.8 percent in the third quarter and 4.5 percent in $\mathrm{Oc}$ tober. Total civilian employment averaged 64.9 percent of the population of labor force age in the third quarter, the highest percentage attained in the past twenty-five years. The major materials capacity utilization index of the Federal Reserve was also at a 25year high, averaging 96.3 percent in the third quarter of 1973.

\section{In Intorion}

Prices continued to increase at a rapid rate in the third quarter. The implicit GNP price deflator rose at a 6.7 percent annual rate from the second to the third quarter, compared with rates of 7.3 and 6 percent in the second and first quarters, respectively.

Wholesale prices have fluctuated sharply in recent months. For the first nine months of the year, however, the net result has been a substantial price rise. Primarily reflecting the movements of wholesale

ivilian Non-Instifutional Population $(16-64)^{*}$

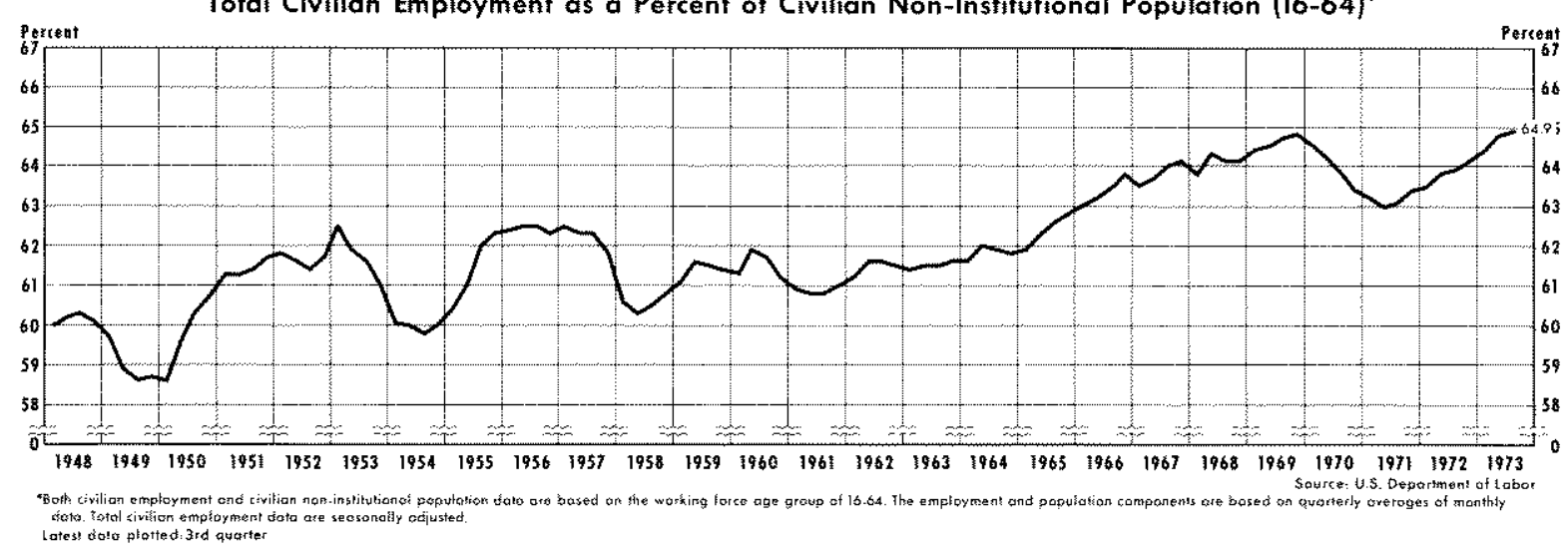




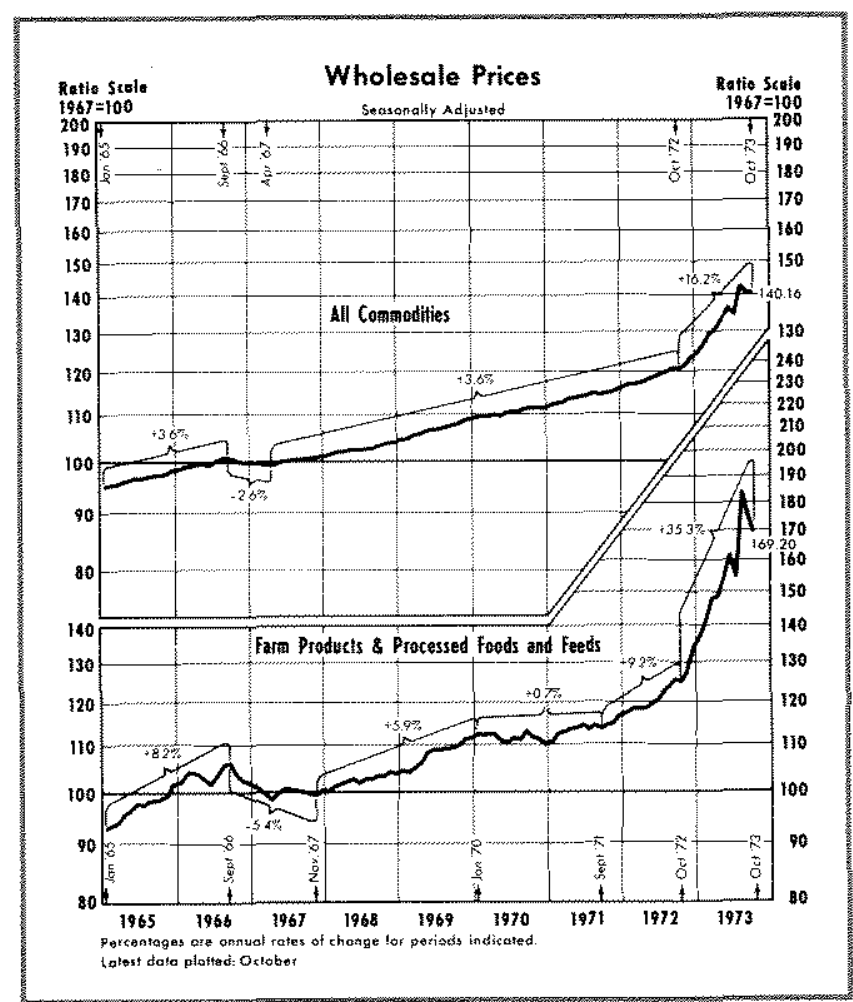

prices of farm products and processed foods and feeds, wholesale prices of all commodities rose sharply in May and June, declined in July, skyrocketed in August, and declined again in September and October. For the six months ending October, wholesale prices of all commodities have risen at a 15.2 percent annual rate, wholesale prices of farm products and processed foods and feeds have increased at a 30.3 percent rate, and wholesale prices of industrial commodities have risen at a 9.2 percent rate.

Consumer prices have increased at a 10.3 percent rate for the three months ending September. For comparison, these prices rose at an 8 percent rate in the first six months of $1973,3.4$ percent in 1972, and at average rates of 4.6 percent from 1967 to 1972 and 1.7 percent from 1957 to 1967 .

\section{Summory}

High rates of inflation accompany the current unemployment rate of 4.5 percent. There is concern that rapid price rises will be accompanied in the near future by a higher unemployment rate and sluggish output growth. These conditions, sometimes called "stagflation," occurred as recently as 1970 and 1971.

Business developments in the third quarter of 1973 gave few clues as to the possible re-occurrence of another period of stagflation. While prices have been increasing rapidly in recent months, the unemployment rate has fallen slightly and the rate of growth of production has slowed toward its fifteen-year trend. An accurate assessment of the course of economic activity may not be possible for several months.

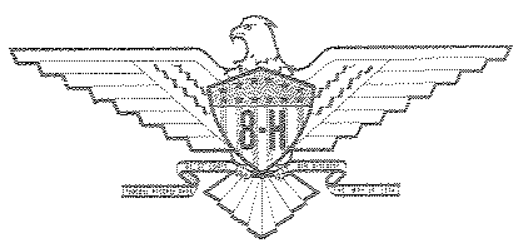

